\title{
Current quality of life and its determinants among opiate-dependent individuals five years after starting methadone treatment
}

\author{
Jessica De Maeyer • Wouter Vanderplasschen • \\ Jan Lammertyn • Chijs van Nieuwenhuizen • \\ Bernard Sabbe $\cdot$ Eric Broekaert
}

Accepted: 12 August 2010/Published online: 26 August 2010

(C) The Author(s) 2010. This article is published with open access at Springerlink.com

\begin{abstract}
Purpose This study explores the current QoL of opiatedependent individuals who started outpatient methadone treatment at least 5 years ago and assesses the influence of demographic, psychosocial, drug and health-related variables on individuals' QoL.

Methods Participants $(n=159)$ were interviewed about their current QoL, psychological distress and severity of drug-related problems, using the Lancashire Quality of Life Profile, the Brief Symptom Inventory and the Addiction Severity Index. Potential determinants of QoL were assessed in a multiple linear regression analysis.

Results Five years after the start of methadone treatment, opiate-dependent individuals report low QoL scores on various domains. No association was found between drugrelated variables and QoL, but a significant negative impact of psychological distress was identified. Severity of psychological distress, taking medication for psychological problems and the inability to change one's living situation
\end{abstract}

J. De Maeyer ( $₫) \cdot$ W. Vanderplasschen · E. Broekaert Department of Orthopedagogics, Ghent University,

H. Dunantlaan 2, 9000 Ghent, Belgium

e-mail: Jessica.Demaeyer@ugent.be

\section{J. Lammertyn}

Faculty of Psychology and Educational Sciences,

Ghent University, H. Dunantlaan 2, 9000 Ghent, Belgium

C. van Nieuwenhuizen

Faculty of Social and Behavioural Sciences, Scientific Research Center for Health and Social Care, Tilburg University, PO BOX 90153, 5000 LE Tilburg, The Netherlands

B. Sabbe

Collaborative Antwerp Psychiatric Research Institute (CAPRI), University of Antwerp, Universiteitsplein 1, 2610 Wilrijk, Belgium were associated with lower QoL. Having at least one good friend and a structured daily activity had a significant, positive impact on QoL.

Conclusions Opiate-dependent individuals' QoL is mainly determined by their psychological well-being and a number of psychosocial variables. These findings highlight the importance of a holistic approach to treatment and support in methadone maintenance treatment, which goes beyond fixing the negative physical consequences of opiate dependence.

Keywords Quality of life - Opiate dependence .

Substitution treatment $\cdot$ Methadone maintenance treatment - Drug abuse · Determinants

\section{Introduction}

Estimations of the prevalence of opiate use in the European Union range from 1 to 6 per thousand inhabitants [1]. Although this number is considerably lower when compared with the prevalence of cocaine, cannabis and other illicit drug use, dependence rates are much higher among opiate users [2]. Opiates, heroin in particular, remain the primary drug for which individuals seek treatment and the vast majority of drug-related infectious diseases and mortality is associated with opiate use [1]. Methadone substitution treatment is the standard, evidence-based treatment for opiate dependence in most countries [3], but recently buprenorphine has been introduced as an alternative substitute drug to reduce heroin use and related health and social problems.

Given the chronic, relapsing nature of drug problems and the various life domains they affect $[4,5]$, the attention for quality of life (QoL) in the field of drug abuse research 
has grown rapidly [6]. The majority of these studies have assessed drug users' health-related quality of life (HRQoL) [7-9], especially among opiate-dependent individuals in treatment [6]. Evidence is available that the HRQoL of opiate-dependent individuals is low in comparison with the general population and individuals suffering from other chronic diseases and most comparable with that of individuals with psychiatric problems [10, 11]. In general, opiate-dependent individuals report poor mental health scores, while their scores for physical functioning are usually considerably higher [12]. HRQoL is a concept frequently misused as a synonym for QoL [13, 14]. It primarily focuses on the effects of a disease on individuals' daily functioning [15], with special attention for their physical and mental health [11, 16].

The comprehensive concept of QoL has a more positive connotation and focuses on persons' overall well-being and satisfaction with life [17]. Such a holistic approach to QoL with attention for drug users' own experiences and expectations is often lacking in drug abuse research. Up till now, the focus in most studies is exclusively on the absence of pathology and individuals' functional status (HRQoL). However, it is necessary to make a distinction between HRQoL and QoL, since individuals' health status may have an impact on QoL, but does not represent it [18]. Health is included as an important domain in most QoL definitions [13], but when individuals are asked to define important domains of QoL health is seldom mentioned as a primary domain $[19,20]$. A qualitative study concerning drug users' perspectives on the concept QoL demonstrated that social inclusion and self-determination are regarded as central components of QoL [20]. On the other hand, some quantitative studies have identified health-related issues as determinants of QoL [21-23], illustrating the possible influence of health status on the concept QoL.

A limited number of studies have reported lower QoL scores for opiate-dependent individuals when compared with the general population or a non-clinical control group $[21,24,25]$. Only recently QoL has become an outcome measure in research on the effectiveness of (various forms of) substitution treatment [3, 26-28]. In general, opiatedependent individuals report low QoL and HRQoL scores at admission to substitution treatment [12]. Participation in substitution treatment brings about positive effects on individuals' HRQoL and QoL, especially during the first months of treatment $[9,28-33]$. However, a stabilization of these improvements or even less favorable outcomes can be noticed from a long-term perspective [30, 34].

A better understanding of determinants that are associated with high QoL scores may advice treatment services and policymakers how they can improve individuals' QoL [35]. Studies that provide information on predictors of $\mathrm{QoL}$ among opiate-dependent persons are limited and have mainly focused on HRQoL. Moreover, these studies have not resulted in unequivocal findings. An inverse relationship between age and HRQoL has been shown in various studies [36-38], while inconsistent findings have been reported regarding the role of gender [10, 30, 36, 38, 39]. The impact of severity of dependence on HRQoL remains unclear $[10,36,40-42]$, but the negative impact of excessive alcohol use on HRQoL has been demonstrated in several studies [8, 41, 43]. Emotional and psychiatric problems (e.g., depression, personality disorders) appear to have a detrimental impact on individuals' HRQoL [36, 44, 45]. Social support may have a positive influence on HRQoL [7], but conflicts with family and partner have been associated with lower HRQoL scores [41]. As demonstrated by Millson and colleagues [36], who identified more than a dozen different determinants of the mental and physical composite scores of the SF-36, opiate-dependent individuals' HRQOL is affected by multiple factors.

Besides the limited number of studies on determinants of QoL, few authors have controlled for the influence of potential covariates in a multivariate design. Consequently, results are often limited to bivariate analyses of correlates of QoL [25, 46, 47]. Despite the specific treatment needs of opiate users, only one study by Bizzarri and colleagues [21] examined the independent impact of dual diagnosis, gender, age and current substance use on QoL of opiatedependent individuals, using the WHOQOL-BREF. This study demonstrated a significant impact of dual diagnosis on all four QoL domains, a negative association of older age and female gender with some domains, while current substance use had no significant impact on QoL. Also, Conroy and colleagues [48] found no association between QoL and drug-using practices (e.g., drug use, sharing of needle equipment) among injecting drug users, but a range of psychosocial factors (e.g., family support, having friends) influenced their current QoL. According to another study, the overall QoL of substance users in treatment was negatively associated with older age, specific medical conditions (i.e., arthritis, ulcers), severity of drug use, being treated in a detoxification unit and recent hospitalization for mental health problems [22]. Finally, improvement of psychiatric symptoms was demonstrated to be the best predictor of increased QoL among severely mentally ill substance abusers [23].

Given the dearth of research on predictors of QoL among opiate-dependent individuals and given the assumption that substitution treatment contributes to the stabilization of opiate users' living situation, the aim of this article is to study the current QoL of persons who started outpatient methadone treatment at least 5 years ago. Furthermore, the influence of recent heroin use and psychological distress on current QoL is assessed, as well as the question which demographic, psychosocial, drug and 
health-related variables are independent predictors of a better QoL.

\section{Methods}

Subjects and data collection

This study was set up as a cross-sectional study of the current QoL of a cohort of opiate-dependent individuals who started outpatient methadone treatment between 1997 and 2002 in the region of Ghent (Belgium). This time frame was chosen, since the first medical-social care center for outpatient methadone treatment (MSOC) was opened in 1997 and since we intended to monitor the current situation of opiate-dependent persons who started methadone treatment at least 5 years ago. No central methadone register was available from the beginning, but it has been estimated that during this period (1997-2002) between 1,000 and 1,500 persons have been involved in methadone treatment in this region [49, 50].

Inclusion criteria for the study were being over 18 years, a diagnosis of opiate dependence at the start of methadone treatment and having started this treatment in the region of Ghent between January 1997 and December 2002. Participants were recruited by the use of various media (e.g., flyers, advertisements in newspapers, interviews on local television and radio), through snowball sampling and by staff members of methadone programs for the group still in treatment. In addition, the regional network of drug treatment agencies informed eligible drug users about the study. Individuals were excluded from the study if the interview could not be administered in Dutch $(n=2)$, if methadone treatment was started after $2002(n=10)$ or outside the region of Ghent $(n=13)$ or when they just received methadone as part of residential detoxification $(n=5)$.

In total, 159 subjects participated in this non-randomized study. Forty-one participants $(25.8 \%)$ were no longer in methadone treatment by the time of the interview, while almost three-quarters of the sample (74.2\%) was currently still on methadone. The mean duration of methadone treatment was 7.6 years $(\mathrm{SD}=4.4)$. A high proportion of the sample $(86.5 \%)$ followed at least two methadone treatment episodes, which is not surprising given the high drop-out rates in substitution treatment [51].

Interviews took place between March 2008 and August 2009 and lasted between 45 and $120 \mathrm{~min}$. Individuals received $20 €$ for participation in the study. A written informed consent was obtained from all participants before the start of the study. Participation was entirely voluntary and confidentiality was assured. Data were collected during face-to-face interviews in a setting of the participants' choice (e.g., at the methadone clinic, in the person's house, in a public place, in a residential treatment center). Interviews focused on respondents' current QoL and on lifetime and current severity of substance use and related problems. The study was approved by the ethical committee of the Faculty of Psychology and Educational Sciences of the Ghent University, in accordance with internationally accepted criteria for research (2006/51).

\section{Instruments}

\section{The Lancashire quality of life profile}

In order to measure individuals' current QoL, we made use of the modified Dutch version of the Lancashire Quality of Life Profile, an instrument commonly used in mental health research $[52,53]$. The LQOLP has been used in a number of studies among opiate-dependent individuals to measure effects of substitution treatment on QoL [26, 33, 34, 46, 54-56]. The LQOLP measures individuals' satisfaction with various QoL domains and their global well-being. The Dutch version of the LQOLP consists of ten subscales: "health", "leisure and social participation", "living situation", "family relations", "finances", "safety", "positive self-esteem", "negative self-esteem" (measured by a modified version of the Self-Esteem Scale; [57]), "framework" and "fulfillment". Perceived QoL or individuals' subjective ratings are assessed on a 7-point Likert scale (from "1. Life cannot be worse" to "7. Life cannot be better") for all domains, except the domains "positive selfesteem", "negative self-esteem", "framework" and "fulfillment". The latter are measured on a 3-point Likert scale but were afterward recoded on a 7-point Likert scale. Low QoL has been defined as "a score below 4" [58]. Besides these specific QoL domains, global well-being is assessed by means of Cantril's ladder [59], a happiness scale [60] and an average life satisfaction score ("how satisfied are you with your life as a whole?"). The LQOLP also contains objective items on various life domains (e.g., occupation, housing situation, psychological problems) [61]. Internal consistency, reliability and validity of the LQOLP have been demonstrated to be satisfactory [52, 53, 62]. For the purpose of this study, we make use of the 10 domain scores, the average life satisfaction score (to measure global well-being) and a total QoL score, a sum score based on the ten specific QoL domain scores [63].

\section{The EuropASI}

In order to measure the severity of substance use and related problems, we used the EuropASI, an adapted and validated version of the Addiction Severity Index (ASI) for the European context [64, 65]. The EuropASI is a semistructured clinical interview, including an assessment on 
seven areas of functioning: medical status, employment/ support, alcohol use, drug use, legal problems, family/ social relationships and psychological problems [66]. An ASI composite score is calculated for each domain (range $0-1$ ), with higher scores indicating higher problem severity [67]. In this study, only the domains "medical status", "alcohol", "drugs" and "legal status" were assessed, since "family", "employment" and "psychological problems" were extensively explored as part of the objective items of the LQOLP. It is a valid approach to assess ASI domains separately.

\section{Brief symptom inventory}

The Dutch version of the Brief Symptom Inventory (BSI), a short version of the widely applied SCL-90, was used to measure psychological distress. This is a validated, multidimensional self-report questionnaire, consisting of 53 items [68]. Psychometric properties of the BSI have been demonstrated to be sufficient [68, 69]. The instrument measures recent psychological complaints (past 7 days) on 9 subscales: "somatization", "obsessive-compulsive", "interpersonal sensitivity", "depression", "anxiety", "hostility", "phobic anxiety", "paranoid ideation" and "psychoticism". Symptoms are rated on a 5-point Likert scale ranging from " 0 . Not at all" to "4. Extremely", with higher scores indicating severe complaints [68]. A Global Severity Index (GSI), an average rating of all 53 items (range 0-4), is calculated as an overall score of psychological functioning. Clinical cut-off scores for psychological distress are available for all 9 subscales and the GSI. The cut-off score of the GSI $(0.70)$ is used as a general measure of psychopathology $[68,69]$. Besides the GSI, the positive symptom distress index (PSDI) measures the intensity of symptoms, while the positive symptom total (PST) represents the number of items indicating psychological distress.

\section{Statistical analyses}

The characteristics of the sample were assessed using descriptive statistics. Domain-based QoL scores and a global well-being score were calculated. A profile was determined, including the number of respondents with low QoL on each domain and low global well-being. Independent samples $t$-tests were used to compare domain scores and global well-being between subjects who recently used heroin and those who did not do so. In addition, respondents who scored higher than the clinical cut-off score for overall psychopathology were compared with those with a GSI below 0.70. A Bonferroni correction was applied to address the problem of multiple comparisons and to protect against type 1 errors in the bivariate analyses. To investigate the independent contribution of individual predictors to QoL, a multiple linear regression model was built using a stepwise search procedure including forward selection as well as backward elimination. The dependent variable (total QoL) was compiled as a sum score of the ten specific domain-based QoL scores. The 28 predictors initially included in the stepwise search were selected based on associations found in previous research and based on existing theories and conceptualizations of QoL [70-72]. The following predictors were entered: gender, age, educational level, employment, having debts, inability to change living situation in the past year, having an intimate relationship, having at least one good friend, having a structured form of daily activities, having been convicted of a crime in the past year, inability to have more contact with own family in the past year, age at first heroin use, age at first methadone use, years of regular heroin use, years of regular methadone use, injecting behavior, number of days in outpatient drug or alcohol treatment during the last 30 days, currently in methadone treatment, number of methadone treatments, taking medication for psychological problems, ever been hospitalized for psychological problems, been a victim of violence in the past year, having chronic medical complaints, ASI drug composite score, ASI alcohol composite score, ASI composite score for medical status, ASI composite score for legal status and the Global Severity Index of the BSI. We acknowledge that the sample size $(n=159)$ is relatively small to test this large number of predictors. Therefore, we used resampling techniques (bootstrapping), which confirmed the validity of the final model. The final model is presented in the "Results" section. All model assumptions were satisfied, and no significant multicollinearity was present between the predictors in the final model. All statistics were done using SPSS 15.0. The statistical significance level was set at $\alpha=0.05$.

\section{Results}

Study sample characteristics

Study participants were predominantly male (74.8\%), with an average age of 36.6 years $(\mathrm{SD}=7.5)$ (see Table 1). Of them, $56.6 \%$ did not complete any form of secondary education. About one-quarter of the participants (26.4\%) currently had a paid job. The largest group of subjects had never been married $(69.8 \%)$ and lived alone $(40.3 \%)$. The mean age of onset of regular heroin use was 21.4 years $(\mathrm{SD}=5.6)$, and they had been consuming heroin regularly for, on average, 10.8 years $(S D=6.7)$. About half of the participants $(49.7 \%)$ reported recent heroin use. The mean age of onset of regular methadone use was 26.0 years 
Table 1 Sociodemographic and drug use-related characteristics of opiate-dependent individuals who started methadone treatment between 1997 and $2002(N=159)$

\begin{tabular}{|c|c|c|c|}
\hline \multirow{2}{*}{\multicolumn{2}{|c|}{$\begin{array}{l}\text { opiate-dependent individuals who started methadone treatment } \\
\text { between } 1997 \text { and } 2002(N=159)\end{array}$}} & \\
\hline & & Characteristics & Sample \\
\hline Characteristics & Sample & Paranoid ideation & $1.13(.85)$ \\
\hline \multirow{2}{*}{ Age $[M(\mathrm{SD})]$} & \multirow{2}{*}{36.6 (7.5) } & Psychoticism & $.78(.74)$ \\
\hline & & Overall psychopathology & $.98(.70)$ \\
\hline
\end{tabular}

Marital status (\%)

Unmarried 69.8

Married $\quad 7.5$

Divorced/widowed 22.6

Intimate relationship (\%) 45.3

One or more children (\%) 50.9

Paid job (\%) 26.4

Age at first use $[M(\mathrm{SD})]$

Heroin

Methadone

$21.4(5.6)$

Years of regular use $[M(\mathrm{SD})]$

Heroin

Methadone

$10.8(6.7)$

$7.6(4.4)$

Injecting behavior (\%)

Ever $\quad 81.8$

In the last 30 days $\quad 27.8$

Substance use in the last 30 days (\%)

$\begin{array}{ll}\text { Alcohol } & 61.0 \\ \text { Cannabis } & 59.2 \\ \text { Benzodiazepines } & 57.2 \\ \text { Heroin } & 49.7 \\ \text { Cocaine } & 31.4 \\ \text { Antidepressants } & 27.2\end{array}$

Average duration of methadone treatment episode (\%)

$<3$ months

3-6 months

$>6$ months

10.5

$>12$ months

71.2

Average dose of methadone (\%)

$\begin{array}{lr}1-39 \mathrm{mg} & 39.5 \\ 40-59 \mathrm{mg} & 24.3 \\ 60-109 \mathrm{mg} & 28.9 \\ >109 \mathrm{mg} & 7.2\end{array}$

Consulted a doctor for psychological problems during $\quad 45.3$

the last year $(\%)$

Taken medication for psychological problems during $\quad 58.5$

the last year $(\%)$

Psychological complaints [M(SD)]

Somatization

$.89(.81)$

Obsessive-compulsive

Interpersonal sensitivity

Depression

Anxiety

Hostility

Phobic anxiety
Table 1 continued

$(\mathrm{SD}=6.4)$. On average, they had been taking methadone during 7.6 years $(\mathrm{SD}=4.4)$. Of the sample, $54.1 \%$ scored above the clinical cut-off score for overall psychopathology, while $87.9 \%$ of the sample scored above the clinical cut-off score for psychological distress for at least one subscale of the BSI. "Paranoid ideation" (65.6\%) was the most frequently reported psychological complaint within the clinical range, followed by "somatization" (56.7\%) and "psychoticism" (55.4\%).

Current quality of life

Individuals who had started outpatient methadone treatment between 5 and 10 years ago appeared most satisfied at the moment with the domains "framework", "positive self-esteem" and "safety" (see Table 2). The domain "framework", which relates to having meaningful perspectives in life, had the highest average satisfaction score. Respondents were least satisfied with their "finances" and "family relations".

While the mean scores provide an overall picture for the total sample, Fig. 1 shows the number of individuals reporting a low QoL $($ score $<4)$ on the various domains. The results are divergent between the domains, with in particular a large number of subjects with a low QoL score for "finances" $(68.6 \%)$ and "family relations" (44.9\%). Also, more than $30 \%$ of the participants had a low QoL concerning "living situation" (34.0\%), "negative

Table 2 Mean scores (range 1-7) for the 10 domains and global well-being of the LQOLP for individuals who started methadone treatment between 1997 and $2002(N=159)$

\begin{tabular}{lcc}
\hline Life domain & Mean & SD \\
\hline Framework & 6.05 & 1.0 \\
Positive self-esteem & 5.96 & 1.3 \\
Safety & 5.23 & 1.0 \\
Fulfillment & 4.69 & 1.1 \\
Negative self-esteem & 4.68 & 1.5 \\
Health & 4.54 & .95 \\
Leisure and social participation & 4.41 & .95 \\
Living situation & 4.34 & 1.4 \\
Family relations & 3.94 & 1.7 \\
Finances & 3.31 & 1.4 \\
Global well-being & 4.04 & 1.5 \\
\hline
\end{tabular}




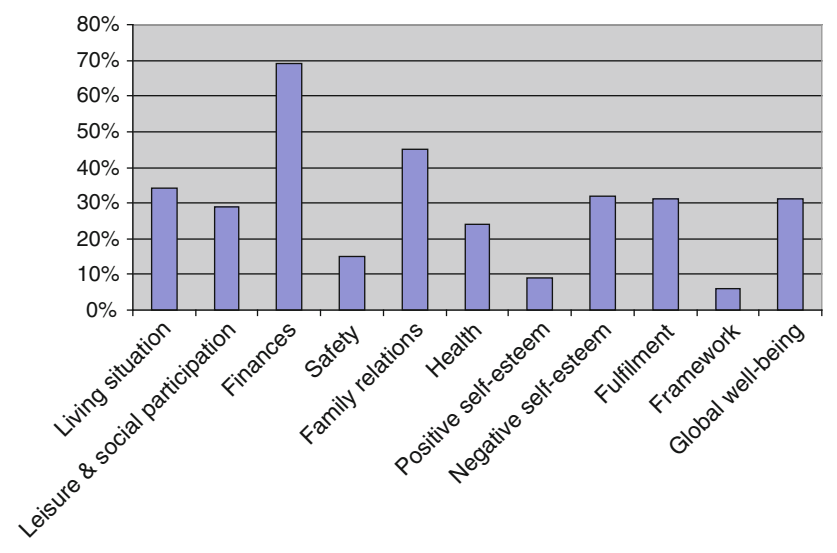

Fig. 1 Proportion of respondents reporting low QoL for each specific domain and global well-being $(N=159)$

self-esteem" (32.1\%) and "fulfillment" (31.4\%). Low satisfaction with fulfillment means that those subjects do not feel able to fulfill their life goals or have difficulties realizing their life goals. In comparison with the other domains, relatively few subjects (24\%) reported low QoL concerning health issues. Overall, $31.4 \%$ of the respondents appear to be dissatisfied with their current global well-being.

Impact of current heroin use and psychological distress on QoL

The sample was split up into two subgroups, based on the presence or absence of recent heroin use (last 30 days). Only the domain score for "finances" was significantly lower among recent heroin users $(t(157)=2.998$, $P=.003$ ), while current heroin use did not affect other QoL domains (Table 3).

A comparison of the respondents who scored higher than the clinical cut-off score for overall psychopathology $(\geq 0.70)$ with those who did not score within the clinical range showed a strong negative impact of current psychological distress on QoL. The former group had significantly lower scores on all QoL domains and for global well-being (Table 4).

\section{Determinants of QoL}

In order to determine which factors influenced total QoL, a multiple linear regression analysis was conducted. The final model obtained through stepwise regression is presented in Table 5. It contains five predictor variables, jointly explaining $60 \%$ of the variance of the total QoL score. Higher scores for psychological distress, inability to change one's living situation and taking medication for psychological complaints were significantly associated with lower QoL. On the other hand, having at least one good friend and having a structured daily activity significantly predicted a higher QoL score. The strongest negative predictor of total QoL was the total score for psychological distress, while having at least one good friend was the predictor with the strongest positive impact on total QoL.

\section{Discussion}

This study revealed low QoL scores on various domains among opiate-dependent individuals 5-10 years after they had started outpatient methadone treatment. Although no general population norms are available with which these results can be compared, a significantly higher proportion of the study sample reported low QoL on six of the ten LQOLP domains in comparison with hospitalized male psychiatric patients [58]. This finding can be partly explained by the high prevalence of psychological complaints in the study sample. Various studies have demonstrated high psychiatric co-morbidity in opiate-dependent individuals (in methadone treatment) [45, 73-75]. Previous studies on QoL of opiate-dependent individuals have reported lower QoL scores among persons with
Table 3 Comparison of the mean scores for the 10 domains and global well-being of the LQOLP between individuals who recently used heroin and those who did not $(N=159)$

* Significant at the Bonferronicorrected $P<0.005$ level

\begin{tabular}{lllrl}
\hline Life domain & $\begin{array}{l}\text { No heroin use } \\
(n=80),[M(\mathrm{SD})]\end{array}$ & $\begin{array}{l}\text { Heroin use } \\
(n=79),[M(\mathrm{SD})]\end{array}$ & $t(d f)$ & $P$ \\
\hline Framework & $6.2(1.0)$ & $5.9(1.0)$ & $1.67(157)$ & .096 \\
Positive self-esteem & $6.0(1.3)$ & $5.9(1.3)$ & $.32(157)$ & .749 \\
Safety & $5.3(1.0)$ & $5.2(1.1)$ & $.52(157)$ & .605 \\
Fulfillment & $4.8(1.1)$ & $4.5(1.1)$ & $1.72(157)$ & .088 \\
Negative self-esteem & $4.8(1.5)$ & $4.6(1.5)$ & $1.00(157)$ & .317 \\
Health & $4.6(0.9)$ & $4.5(1.0)$ & $.15(157)$ & .882 \\
Leisure and social participation & $4.5(0.9)$ & $4.3(1.0)$ & $1.65(157)$ & .100 \\
Living situation & $4.4(1.4)$ & $4.3(1.5)$ & $.16(157)$ & .874 \\
Family relations & $4.1(1.6)$ & $3.7(1.8)$ & $1.38(157)$ & .168 \\
Finances* & $3.6(1.4)$ & $3.0(1.2)$ & $3.00(157)$ & $.003 *$ \\
Global well-being & $4.2(1.6)$ & $3.8(1.4)$ & $1.71(157)$ & .089 \\
\hline
\end{tabular}


Table 4 Comparison of the mean scores for the 10 domains and global well-being of the LQOLP between persons with an overall psychopathology of $\geq 0.70$ score and persons with a lower score $(N=157)$

* Significant at the Bonferronicorrected $P<0.005$ level

\begin{tabular}{lllll}
\hline Life domain & $\begin{array}{l}\text { No psychopathology } \\
(n=72),[M(\mathrm{SD})]\end{array}$ & $\begin{array}{l}\text { Psychopathology } \\
(n=85),[M(\mathrm{SD})]\end{array}$ & $t(d f)$ & $P$ \\
\hline Framework & $6.3(0.8)$ & $5.8(1.1)$ & $3.09(152.96)$ & $.002^{*}$ \\
Positive self-esteem & $6.6(0.8)$ & $5.5(1.4)$ & $6.17(133.66)$ & $.000^{*}$ \\
Safety & $5.5(0.9)$ & $5.0(1.1)$ & $3.16(153.06)$ & $.002^{*}$ \\
Fulfillment & $5.2(1.0)$ & $4.2(1.0)$ & $5.70(155)$ & $.000^{*}$ \\
Negative self-esteem & $5.5(1.4)$ & $4.0(1.2)$ & $7.08(155)$ & $.000^{*}$ \\
Health & $5.0(0.8)$ & $4.2(0.9)$ & $6.07(155)$ & $.000^{*}$ \\
Leisure and social participation & $4.7(0.7)$ & $4.2(1.0)$ & $3.98(147.86)$ & $.000^{*}$ \\
Living situation & $4.8(1.2)$ & $4.0(1.5)$ & $3.60(154.47)$ & $.000^{*}$ \\
Family relations & $4.4(1.6)$ & $3.6(1.7)$ & $3.02(155)$ & $.003^{*}$ \\
Finances* & $3.7(1.3)$ & $3.0(1.3)$ & $3.17(155)$ & $.002^{*}$ \\
Global well-being & $4.5(1.4)$ & $3.7(1.5)$ & $3.36(155)$ & $.001^{*}$ \\
\hline
\end{tabular}

Table 5 Final model of the linear multivariate regression analysis including significant predictors of total QoL

\begin{tabular}{llrrr}
\hline Remaining predictors & $B$ & SE & Beta & $t$ \\
\hline (Constant) & 5.420 & .138 & .000 \\
Global Severity Index/psychological distress & -.573 & .060 & -.539 & 39.36 \\
Inability to change living situation & -.441 & .093 & -.252 & -9.50 \\
Medication for psychological complaints & -.300 & .083 & -.197 & .000 \\
Good friend & .309 & .089 & .184 & .000 \\
Structured daily activities & .228 & .087 & .147 & .000 \\
\hline
\end{tabular}

$R^{2}=.616$

Adjusted $R^{2}=.602$

$P<.05$

co-occurring psychiatric problems when compared with individuals without psychiatric co-morbidity [12]. Similar findings can be observed in studies among persons with severe mental illnesses, in which a negative effect of substance abuse on QoL has been demonstrated [76, 77]. It appears that individuals with a so-called dual diagnosis are more vulnerable for having a poor QoL. Given the high prevalence of psychological symptoms in opiate-dependent individuals, it can be questioned whether it would not be more appropriate to develop integrated mental health and substance abuse services as the standard of care [78].

Persons who started methadone treatment more than 5 years ago are generally dissatisfied with their "finances". This has also been observed in other studies that have used the LQOLP to assess the effectiveness of opiate substitution treatment $[33,34,54-56]$. The dissatisfaction with their financial situation may not be surprising, given the high cost of supporting a drug consumption habit [79] and drug users' substantial debts. Individuals' poor education and unemployment may further affect their social and economic situation [45, 80, 81]. Yet, the domain "finances" also appears to be the domain with the lowest satisfaction among the general population [82].
The high mean score on the domain "framework" shows that opiate-dependent individuals have a sense of purpose with their life and future plans that give them satisfaction. Life meaning is important to buffer stress, and has in its turn a positive influence on QoL [83]. Studies by Moomal [84] and Zika and Chamberlain [85] have demonstrated a clear association between life meaning and psychological well-being. Life meaning is a domain that needs more attention in QoL measurements, given the high importance that is attributed to this domain by persons with drug and mental health problems [20, 53]. The high proportion of subjects who report a low QoL on the domain "fulfillment" indicates that many opiate-dependent individuals think it will be very difficult to actually realize their desired life goals. Experiences of stigma [86] and discrimination [87] often hinder drug users in their daily functioning and are associated with poor mental and physical health [88].

Low scores on one QoL domain do not necessarily imply low scores on another domain, illustrating the necessity to assess QoL from a multidimensional perspective. The relatively high scores on the domain "health" demonstrate the appropriateness of methadone programs 
for reducing health problems, but-in combination with the previous observation-also stress the need for looking beyond health-related aspects. Generally, measuring QoL should be given a more prominent role in the assessment and monitoring of drug problems, starting from individuals' needs and expectations in order to postulate and adjust treatment goals [89].

To our knowledge, this is the first study applying a multivariate design to assess the independent impact of various demographic, psychosocial, drug- and health-related determinants on QoL among opiate-dependent individuals who started methadone treatment at least 5 years ago. This study confirms the findings of Conroy [48] and Bizzarri [21], who found no association between drugrelated variables and the QoL of injecting drug users. Neither the ASI composite scores for drugs and alcohol, nor other drug-related variables, nor current treatment status were significant determinants of QoL. Also, in a validation study of the IDUQOL [90], very low and nonsignificant correlations were observed between several drug-related variables and overall QoL. Bivariate comparisons of study subjects who recently used heroin and persons who did not do so, only showed a significantly lower mean QoL score for the domain "finances" among current heroin users. These findings illustrate the limited influence of severity of drug use problems on current $\mathrm{QoL}$ and highlight the need for treatment goals other than stopping or reducing drug use. Being abstinent from drugs or reduced drug problem severity is not necessarily accompanied by improvements in QoL, since giving up the positive aspects associated with drug use (e.g., prestige/ status in the drug scene) and coping with various stressors (e.g., loneliness, boredom, discrimination) may have a negative impact on individuals' QoL [20].

Psychological distress appears to have the strongest negative impact on current QoL. As much as $25 \%$ of the variance of total QoL was independently explained by the severity of psychological distress. Also, taking medication for psychological complaints has a strong negative impact on QoL. Both determinants demonstrate the strong negative impact of psychological problems on the current $\mathrm{QoL}$ of opiate-dependent individuals. Consequently, early identification of psychological problems based on systematic assessment procedures and attention for the issue of co-morbidity during the treatment process is a prerequisite in methadone treatment.

Contextual factors, such as having a good friend and a structured daily activity, had a significant positive influence on the total QoL of opiate-dependent individuals. The protective role of social support on drug consumption [91, 92] and retention in treatment [93] has been shown in various studies. The observation that social networks have a positive impact on opiate-dependent persons' QoL stresses the need for establishing individuals' (non-professional) social networks during and after methadone treatment in order to enhance their social inclusion. This is further illustrated by the positive impact of having daily activities on total QoL: not necessarily employment, but having a meaningful plan for the day showed a positive association with total QoL. Meaningful day activities and social support are both generic determinants of $\mathrm{QoL}$ and have also been identified as protective factors for QoL among the general population and specific subpopulations (e.g., persons with depressive disorders, disabilities) [94-98]. The inability to change one's living situation during the past year further had a significant negative impact on persons' total QoL. The importance of stable housing for individuals' QoL has been recognized in various studies on QoL of dually diagnosed individuals [48, 99]. These independent correlates of QoL illustrate the need to assist opiate users in methadone treatment with housing and occupational issues. The influence of elements other than health-related factors (e.g., having an occupation, a good friend) on QoL cannot be underestimated. Due to a unilateral focus on health, caregivers may only have a partial picture of clients' QoL and the various factors influencing it [19]. Furthermore, improving one's QoL [17, 100] and tackling non-health-related problems (e.g., family relations, legal status, employment status) have been identified as the main reasons for going into treatment [38].

Ultimately, this study has revealed that opiate-dependent individuals still need support on various life domains 5-10 years after starting methadone treatment and that a satisfactory QoL is in particular mediated by psychological well-being and some psychosocial variables. Consequently, a more holistic approach to methadone maintenance-and drug treatment in general-is recommended, which goes beyond pharmaceutical maintenance and medical care to include specific attention for psychological complaints and support in housing, occupational and social inclusion issues $[36,45,101]$.

\section{Limitations of the study}

Some limitations of this study should be taken into account. First, the sample size $(n=159)$ was relatively small. Findings may therefore not be generalized to other groups of opiate users. Second, respondents were not selected randomly, nor did we apply a controlled design. It is unclear if the sample was fully representative for the group of opiate-dependent individuals starting methadone treatment $5-10$ years ago $(n=1,500)$, but the age and gender distribution of the sample was identical to that of persons in outpatient methadone treatment in the region of Ghent between 1997 and 2002 [50]. The representativeness 
of the sample was enhanced by applying various strategies to recruit study participants (e.g., flyers, media campaign, contacts with drug, health and social services). It would further be interesting to focus in future research on the QoL of other groups of drug users (e.g., cocaine users, opiate users out of treatment) [102] and compare these findings with those reported here. Third, given the cross-sectional design of the study, causality could not be examined. This study only reports associations, because possible determinants and outcomes were measured at the same time. Future longitudinal research should address issues of directionality and linearity. Fourth, psychological distress was measured by means of a short symptom checklist (BSI). Consequently, the prevalence of psychiatric disorders was not assessed, as no standardized diagnostic instrument was used. Still, validation studies have shown high correlations between BSI subscales and diagnostic instruments measuring the same constructs [68]. Fifth, 60\% of the variance of total QoL was explained by our final regression model, illustrating that other factors (not included in the model) will have had an impact on total QoL. Qualitative in-depth interviews could provide more information on how drug users perceive $\mathrm{QoL}$ and on factors that affect the QoL of drug-using individuals [20, 103]. Finally, given the conceptual discrepancy between QoL and HRQoL, researchers need to make explicit what they are measuring exactly. Therefore, it would be interesting to compare both concepts-QoL and HRQoL-in future research, in order to illustrate the different conceptualization of both concepts.

Open Access This article is distributed under the terms of the Creative Commons Attribution Noncommercial License which permits any noncommercial use, distribution, and reproduction in any medium, provided the original author(s) and source are credited.

\section{References}

1. European Monitoring Centre for Drugs, Drug Addiction (EMCDDA). (2009). Stand van de drugsproblematiek in Europa: Jaarverslag 2009. [Annual report: 2009 Annual report of the state of the drugs problem in Europe]. Luxemburg: Bureau voor officiële publicaties der Europese gemeenschappen.

2. European Monitoring Centre for Drugs, Drug Addiction (EMCDDA). (2008). Stand van de drugsproblematiek in Europa: Jaarverslag 2008. [Annual report: 2008 Annual report of the state of the drugs problem in Europe]. Luxemburg: Bureau voor officiële publicaties der Europese gemeenschappen.

3. Amato, L., Davoli, M., Perucci, C. A., Ferri, M., Faggiano, F., \& Mattick, R. P. (2005). An overview of systematic reviews of the effectiveness of opiate maintenance therapies: Available evidence to inform clinical practice and research. Journal of Substance Abuse Treatment, 28(4), 321-329.

4. McLellan, A. T., Lewis, D. C., O’Brien, C. P., \& Kleber, H. D. (2000). Drug dependence, a chronic medical illness. Implications for treatment, insurance, and outcomes evaluation.
JAMA-Journal of the American Medical Association, 284(13), 1689-1695.

5. Vanderplasschen, W., Rapp, R. C., Wolf, J., \& Broekaert, E. (2004). The development and implementation of case management for substance use disorders in North America and Europe. Psychiatric Services, 55(8), 913-922.

6. Zubaran, C., \& Foresti, K. (2009). Quality of life and substance use: Concepts and recent tendencies. Current Opinion in Psychiatry, 22(3), 281-286.

7. Preau, M., Protopopescu, C., Spire, B., Sobel, A., Dellamonica, P., Moatti, J. P., et al. (2007). Health related quality of life among both current and former injection drug users who are HIVinfected. Drug and Alcohol Dependence, 86(2-3), 175-182.

8. Senbanjo, R., Wolff, K., \& Marshall, J. (2006). Excessive alcohol consumption is associated with reduced quality of life among methadone patients. Addiction, 102(2), 257-263.

9. Villeneuve, P. J., Challacombe, L., Strike, C. J., Myers, T., Fischer, B., Shore, R., et al. (2006). Change in health-related quality of life of opiate users in low-threshold methadone programs. Journal of Substance Use, 11(2), 137-149.

10. Ryan, C. F., \& White, J. M. (1996). Health status at entry to methadone maintenance treatment using the SF-36 health survey questionnaire. Addiction, 91(1), 39-45.

11. Millson, P. E., Challacombe, L., Villeneuve, P. J., Fischer, B., Strike, C. J., Myers, T., et al. (2004). Self-perceived health among Canadian opiate users. A comparison to the general population and to other chronic disease populations. Canadian Journal of Public Health, 95(2), 99-103.

12. De Maeyer, J., Vanderplasschen, W., \& Broekaert, E. (2010). Quality of life among opiate-dependent individuals: A review of the literature. International Journal of Drug Policy. doi: 10.1016/j.drugpo.2010.01.010.

13. Muldoon, M. F., Barger, S. D., Flory, J. D., \& Manuck, S. B. (1998). What are quality of life instruments measuring? British Medical Journal, 316(7130), 542-545.

14. Cummins, R. A., Lau, A., \& Stokes, M. (2004). HRQOL and subjective well-being: Noncomplementary forms of outcome measurement. Expert Review of Pharmacoeconomics \& Outcomes Research, 4(4), 413-420.

15. Wiklund, I. (2004). Assessment of patient-reported outcomes in clinical trials: The example of health-related quality of life. Fundamental and Clinical Pharmacology, 18(3), 351-363.

16. Mooney, A. (2006). Quality of life: Questionnaires and questions. Journal of Health Communication, 11, 327-341.

17. Laudet, A. B., Becker, J. B., \& White, W. L. (2009). Don't wanna go through that madness no more: Quality of life satisfaction as predictor of sustained remission from illicit drug misuse. Substance Use and Misuse, 44(2), 227-252.

18. Smith, K. W., Avis, N. E., \& Assmann, S. F. (1999). Distinguishing between quality of life and health status in quality of life research: A meta-analysis. Quality of Life Research, 8(5), 447-459.

19. Anderson, K. L., \& Burckhardt, C. S. (1999). Conceptualization and measurement of quality of life as an outcome variable for health care intervention and research. Journal of Advanced Nursing, 29(2), 298-306.

20. De Maeyer, J., Vanderplasschen, W., \& Broekaert, E. (2009). Exploratory study on drug users' perspectives on quality of life: More than health-related quality of life? Social Indicators Research, 90(1), 107-126.

21. Bizzarri, J., Rucci, P., Vallotta, A., Girelli, M., Scandolari, A., Zerbetto, E., et al. (2005). Dual diagnosis and quality of life in patients in treatment for opioid dependence. Substance Use and Misuse, 40(12), 1765-1776.

22. Smith, K. W., \& Larson, M. (2003). Quality of life assessments by adult substance abusers receiving publicly funded treatment 
in Massachusetts. The American Journal of Drug and Alcohol Abuse, 29, 323-335.

23. Schaar, I., \& Öjehagen, A. (2003). Predictors of improvement in quality of life of severely mentally ill substance abusers during 18 months of co-operation between psychiatric and social services. Social Psychiatry and Psychiatric Epidemiology, 38(2), 83-87.

24. Luty, S., \& Arokiadass, S. M. R. (2008). Satisfaction with life and opioid dependence. Substance Abuse Treatment, Prevention, and Policy, 3(2). doi:10.1186/1747-597X-3-2

25. Fassino, S., Abbate Daga, G., Delsedime, N., Rogna, L., \& Boggio, S. (2004). Quality of life and personality disorders in heroin abusers. Drug and Alcohol Dependence, 76(1), 73-80.

26. Winklbaur, B., Jagsch, R., Ebner, N., Thau, K., \& Fischer, G. (2008). Quality of life in patients receiving opioid maintenance therapy. European Addiction Research, 14(2), 99-105.

27. Maremmani, I., Pani, P. P., Pacini, M., \& Perugi, G. (2007). Substance use and quality of life over 12 months among buprenorphine maintenance-treated and methadone maintenancetreated heroin-addicted patients. Journal of Substance Abuse Treatment, 33(1), 91-98.

28. Padaiga, Z., Subata, E., \& Vanagas, G. (2007). Outpatient methadone maintenance treatment program. Quality of life and health of opioid-dependent persons in Lithuania. Medicina (Kaunas), 43(3), 235-241.

29. Torrens, M., San, L., Martinez, A., Castillo, C., DomingoSalvany, A., \& Alonso, J. (1997). Use of the Nottingham health profile for measuring health status of patients in methadone maintenance treatment. Addiction, 92(6), 707-716.

30. Habrat, B., Chmielewska, K., Baran-Furga, H., Keszycka, B., \& Taracha, E. (2002). Subjective quality of life in opiate dependent patients before admission, after six months and oneyear participation in methadone program. Przeglad Lekarski, 59(4-5), 351-354.

31. March, J. C., Oviedo-Joekes, E., Perea-Milla, E., Carrasco, F., \& The PEPSA team. (2006). Controlled trial of prescribed heroin in the treatment of opioid addiction. Journal of Substance Abuse Treatment, 31(2), 203-211.

32. O'Brien, S., Mattick, R. P., White, J., Breen, C., Kimber, J., Ritter, A., et al. (2006). Maintenance pharmacotherapy for opioid dependence and SF-36 health status: A comparison with general population norms and other chronic disorders. Addictive Disorders \& Their Treatment, 5(4), 155-164.

33. Giacomuzzi, S. M., Riemer, Y., Kemmler, G., Ertl, M., Richter, R., Rössler, H., et al. (2001). Subjektives Wohlbefinden und somatische Merkmale bei Methadonsubstitution. Evaluierung bei 61 Heroinabhängigen. Fortschritte der Medizin, 119(3-4), 103-108.

34. Giacomuzzi, S. M., Ertl, M., Kemmler, G., Riemer, Y., \& Vigl, A. (2005). Sublingual buprenorphine and methadone maintenance treatment: A three-year Follow-up of quality of life assessment. The Scientific World Journal, 5, 452-468.

35. Carr, A. J., Gibson, B., \& Robinson, P. G. (2001). Measuring quality of life-Is quality of life determined by expectations or experience? British Medical Journal, 322(7296), 1240-1243.

36. Millson, P. E., Challacombe, L., Villeneuve, P. J., Strike, C. J., Fischer, B., Myers, T., et al. (2006). Determinants of healthrelated quality of life of opiate users at entry to low-threshold methadone programs. European Addiction Research, 12(2), $74-82$.

37. Lofwall, M. R., Brooner, R. K., Bigelow, G. E., Kindbom, K., \& Strain, E. C. (2005). Characteristics of older opioid maintenance patients. Journal of Substance Abuse Treatment, 28(3), 265-272.

38. Deering, D. E., Frampton, M. A., Horn, J., Sellman, J. D., Adamson, S. J., \& Potiki, T. L. (2004). Health status of clients receiving methadone maintenance treatment using the SF-36 health survey questionnaire. Drug and Alcohol Review, 23(3), 273-280.

39. Haug, N. A., Sorensen, J. L., Lollo, N. D., Gruber, V. A., Delucchi, K. L., \& Hall, S. M. (2005). Gender differences among HIV-positive methadone maintenance patients enrolled in a medication adherence trial. AIDS Care, 17(8), 1022-1029.

40. Astals, M., Domingo-Salvany, A., Castillo Buenaventura, C., Tato, J., Vazquez, J. M., Martín-Santos, R., et al. (2008). Impact of substance dependence and dual diagnosis on the quality of life of heroin users seeking treatment. Substance Use and Misuse, 43(5), 612-632.

41. Karow, A., Verthein, U., Krausz, M., \& Schäfer, I. (2008). Association of personality disorders, family conflicts and treatment with quality of life in opiate addiction. European Addiction Research, 14(1), 38-46.

42. Puigdollers, E., Domingo-Salvany, A., Brugal, M. T., Torrens, M., Alvarós, J., Castillo, C., et al. (2004). Characteristics of heroin addicts entering methadone maintenance treatment: Quality of life and gender. Substance Use and Misuse, 39(9), $1353-1368$.

43. Costenbader, E. C., Zule, W. A., \& Coomes, C. M. (2007). The impact of illicit drug use and harmful drinking on quality of life among injection drug users at high risk for hepatitis $\mathrm{C}$ infection. Drug and Alcohol Dependence, 89(2-3), 251-258.

44. Batki, S. L., Canfield, K. M., Smyth, E., \& Ploutz-Snyder, R. (2009). Health-related quality of life in methadone maintenance patients with untreated hepatitis $\mathrm{C}$ virus infection. Drug and Alcohol Dependence, 101(3), 176-182.

45. Carpentier, P. J., Krabbe, P. F. M., van Gogh, M. T., Knapen, L. J. M., Buitelaar, J. K., \& de Jong, C. A. J. (2009). Psychiatric comorbidity reduces quality of life in chronic methadone maintained patients. American Journal on Addictions, 18(6), 470-480.

46. Giacomuzzi, S. M., Riemer, Y., Ertl, M., Kemmler, G., Rössler, H., Hinterhuber, H., et al. (2005). Gender differences in healthrelated quality of life on admission to a maintenance treatment program. European Addiction Research, 11(2), 69-75.

47. Becker, S. J., Curry, J. F., \& Yang, C. M. (2009). Longitudinal association between frequency of substance use and quality of life among adolescents receiving a brief outpatient intervention. Psychology of Addictive Behaviors, 23(3), 482-490.

48. Conroy, E., Kimber, J., Dolan, K., \& Day, C. (2008). An examination of the quality of life among rural and outer metropolitan injecting drug users in NSW, Australia. Addiction Research \& Theory, 16(6), 607-617.

49. Colpaert, K., Vanderplasschen, W., \& Broekaert, E. (2007). Comparison of single and multiple agency clients in substance abuse treatment services. European Addiction Research, 13(3), $156-166$.

50. Vanderplasschen, W., Colpaert, K., Lievens, K., \& Broekaert, E. (2003). De Oost-Vlaamse drughulpverlening in cijfers: Kenmerken, zorggebruik en uitstroom van personen in behandeling. [The drug treatment in East-Flanders in figures: Characteristics, service utilisation and dropout of persons in treatment]. (Orthopedagogische Reeks Gent, 15). Gent: Universiteit Gent, Vakgroep Orthopedagogiek.

51. Haskew, M., Wolff, K., Dunn, J., \& Bearn, J. (2008). Patterns of adherence to oral methadone: Implications for prescribers. Journal of Substance Abuse Treatment, 35(2), 109-115.

52. van Nieuwenhuizen, C., Schene, A. H., Koeter, M. W. J., \& Huxley, P. J. (2001). The Lancashire quality of life profile: Modification and psychometric evaluation. Social Psychiatry and Psychiatric Epidemiology, 36(1), 36-44.

53. van Nieuwenhuizen, C., Schene, A., Boevink, W., \& Wolf, J. (1998). The Lancashire quality of life profile: First experiences 
in The Netherlands. Community Mental Health Journal, 34(5), 513-524

54. Giacomuzzi, S., Kemmler, G., Ertl, M., \& Riemer, Y. (2006). Opioid addicts at admission vs. slow-release oral morphine, methadone, and sublingual buprenorphine maintenance treatment participants. Substance Use and Misuse, 41(2), 223-244.

55. Giacomuzzi, S. M., Riemer, Y., Ertl, M., Kemmler, G., Rössler, H., Hinterhuber, H., et al. (2003). Buprenorphine versus methadone maintenance treatment in an ambulant setting: A healthrelated quality of life assessment. Addiction, 98(5), 693-702.

56. Fischer, G., Eder, H., Peternell, A., \& Windhaber, J. (2000). Lebensqualität gravider substanzabhängiger Frauen unter oraler Erhaltungstherapie mit synthetischen Opioiden. Nervenheilkunde, 19, 205-211.

57. Rosenberg, M. (1965). Society and the adolescent self-image. Princeton: Princeton University Press.

58. van Nieuwenhuizen, C., \& Nijman, H. (2009). Quality of life of forensic psychiatric inpatients. International Journal of Forensic Mental Health, 8(1), 9-15.

59. Cantril, H. (1965). The pattern of human concerns. New Brunswick, NJ: Rutgers University Press.

60. Gurin, G., Veroff, J., \& Feld, S. (1960). Americans view their mental health. New York: Basic Books.

61. Ruggeri, M., Warner, R., Bisoffi, G., \& Fontecedro, L. (2001). Subjective and objective dimensions of quality of life in psychiatric patients: A factor analytical approach-The South Verona Outcome Project 4. British Journal of Psychiatry, 178(3), 268-275.

62. Oliver, J. P. J., Huxley, P. J., Priebe, S., \& Kaiser, W. (1997). Measuring the quality of life of severely mentally ill people using the Lancashire quality of life profile. Social Psychiatry and Psychiatric Epidemiology, 32(2), 76-83.

63. Schneider, J., Wooff, D., Carpenter, J., Brandon, T., \& McNiven, F. (2002). Community mental healthcare in England: Associations between service organisation and quality of life. Health \& Social Care in the Community, 10(6), 423-434.

64. Kokkevi, A., \& Hartgers, C. (1995). EuropASI: European adaptation of a multidimensional assessment instrument for drug and alcohol dependence. European Addiction Research, 1(4), 208-210.

65. McLellan, A. T., Kushner, H., Metzger, D., Peters, R., Smith, I., Grissom, G., et al. (1992). The 5th edition of the addiction severity index. Journal of Substance Abuse Treatment, 9(3), 199-213.

66. McLellan, A. T., Luborsky, L., Woody, G. E., \& O’Brien, C. P. (1980). Improved diagnostic evaluation instrument for substance abuse patients-Addiction severity index. Journal of Nervous and Mental Disease, 168(1), 26-33.

67. Koeter, M. W. J., \& Hartgers, C. (1996). Preliminary procedure for the computation of the EuropASI composite scores. Amsterdam: AIAR.

68. De Beurs, E. (2006). Brief symptom inventory, handleiding. Leiden: PITS BV

69. Derogatis, L. R., \& Melis aratos, N. (1983). The brief symptom inventory: An introductory report. Psychological Medicine, 13, 595-605.

70. Katschnig, H. (2006). How useful is the concept of quality of life in psychiatry? In H. Katschnig, H. Freeman, \& N. Sartorius (Eds.), Quality of life in mental disorders (2nd ed., pp. 3-17). West Sussex: Wiley.

71. Rapley, M. (2003). Quality of life research: A critical introduction. London: Sage Publications.

72. Schalock, R. (1996). Quality of Life. Volume 1: Conceptualization and measurement. Washington: American Association on Mental Retardation.
73. Rodríguez-Llera, M. C., Domingo-Salvany, A., Brugal, M. T., Silva, T. C., Sánchez-Niubó, A., Torrens, M., et al. (2006). Psychiatric comorbidity in young heroin users. Drug and Alcohol Dependence, 84(1), 48-55.

74. Callaly, T., Trauer, T., Munro, L., \& Whelan, G. (2001). Prevalence of psychiatric disorder in a methadone maintenance population. Australian and New Zealand Journal of Psychiatry, 35(5), 601-605.

75. Cacciola, J. S., Alterman, A. I., Rutherford, M. J., McKay, J. R., \& Mulvaney, F. D. (2001). The relationship of psychiatric comorbidity to treatment outcomes in methadone maintained patients. Drug and Alcohol Dependence, 61(3), 271-280.

76. Urbanoski, K. A., Cairney, J., Adlaf, E., \& Rush, B. (2007). Substance abuse and quality of life among severely mentally ill consumers. A longitudinal modelling analysis. Social Psychiatry and Psychiatric Epidemiology, 42(10), 810-818.

77. Lam, J. A., \& Rosenheck, R. A. (2000). Correlates of improvement in quality of life among homeless persons with serious mental illness. Psychiatric Services, 51(1), 116-118.

78. Drake, R. E., Mueser, K. T., \& Brunette, M. F. (2007). Management of persons with co-occurring severe mental illness and substance use disorder: Program implications. World Psychiatry, 6(3), 131-136.

79. Information Services. (2007). Drug misuse statistics 2007. Edinburgh: ISD Publications.

80. Vanderplasschen, W., De Bourdeaudhuij, I., \& Van Oost, P. (2002). Co-ordination and continuity of care in substance abuse treatment-An evaluation study in Belgium. European Addiction Research, 8(1), 10-21.

81. Meulenbeek, P. A. M. (2000). Addiction problems and methadone treatment. Journal of Substance Abuse Treatment, 19(2), 171-174.

82. Evans, S., \& Huxley, P. (2002). Studies of quality of life in the general population. International Review of Psychiatry, 14(3), 203-211.

83. Laudet, A. B., Morgen, K., \& White, W. L. (2006). The role of social supports, spirituality, religiousness, life meaning and affiliation with 12-step fellowships in quality of life satisfaction among individuals in recovery from alcohol and drug problems. Alcoholism Treatment Quarterly, 24(1-2), 33-73.

84. Moomal, Z. (1999). The relationship between meaning in life and mental well-being. South African Journal of Psychology, 29(1), 36-41.

85. Zika, S., \& Chamberlain, K. (1992). On the relation between meaning in life and psychological well-being. British Journal of Psychology, 83(1), 133-145.

86. Murphy, S., \& Irwin, J. (1992). Living with the dirty secretProblems of disclosure for methadone-maintenance clients. Journal of Psychoactive Drugs, 24(3), 257-264.

87. Young, M., Stuber, J., Ahern, J., \& Galea, S. (2005). Interpersonal discrimination and the health of illicit drug users. American Journal of Drug and Alcohol Abuse, 31(3), 371-391.

88. Ahern, J., Stuber, J., \& Galea, S. (2007). Stigma, discrimination and the health of illicit drug users. Drug and Alcohol Dependence, 88(2-3), 188-196.

89. Kolind, T., Vanderplasschen, W., \& De Maeyer, J. (2009). Dilemmas when working with substance abusers with multiple and complex problems: The case manager's perspective. International Journal of Social Welfare, 18(3), 270-280.

90. Hubley, A. M., Russell, L. B., Palepu, A. (2005). Injection drug use quality of life scale (IDUQOL): A validation study. Health and Quality of Life Outcomes, 3(43). http://www.hqlo.com/ content/3/1/43.

91. Garmendia, M. L., Alvarado, M. E., Montenegro, M., \& Pino, P. (2008). Social support as protective factor of recurrence after 
drug addiction treatment. Revista Medica de Chile, 136(2), 169-178.

92. Mizuno, Y., Purcell, D. W., Dawson-Rose, C., Parsons, J. T., \& Team, The. S. U. D. I. S. (2003). Correlates of depressive symptoms among HIV-positive injection drug users: The role of social support. AIDS Care, 15(5), 689-698.

93. Dobkin, P. L., De Civita, M., Paraherakis, A., \& Gill, K. (2002). The role of functional social support in treatment retention and outcomes among outpatient adult substance abusers. Addiction, 97(3), 347-356.

94. Diener, E., \& Ryan, K. (2009). Subjective well-being: A general overview. South African Journal of Psychology, 39(4), 391-406.

95. Chung, L., Pan, A. W., \& Hsiung, P. C. (2009). Quality of life for patients with major depression in Taiwan: A model-based study of predictive factors. Psychiatry Research, 168(2), 153-162.

96. Ay-Woan, P., Sarah, C. P. Y., LyInn, C., Tsyr-Jang, C., \& PingChuan, H. (2006). Quality of life in depression: Predictive models. Quality of Life Research, 15(1), 39-48.

97. Schalock, R., \& Verdugo Alonso, M. A. (2002). Handbook on quality of life for human service practitioners. Washington: American Association on Mental Retardation.
98. Viemerö, V., \& Krause, C. (1998). Quality of life in individuals with physical disabilities. Psychotherapy and Psychosomatics, 67(6), 317-322.

99. Bebout, R. R., Drake, R. E., Xie, H. Y., McHugo, G. J., \& Harris, M. (1997). Housing status among formerly homeless dually diagnosed adults. Psychiatric Services, 48(7), 936-941.

100. Stark, M. J., \& Campbell, B. K. (1991). A psychoeducational approach to methadone-maintenance treatment-A survey of client reactions. Journal of Substance Abuse Treatment, 8(3), $125-131$.

101. Vanagas, G., Padaiga, Z., \& Bagdonas, E. (2006). Cost-utility analysis of methadone maintenance treatment: A methodological approach. Substance Use and Misuse, 41, 87-101.

102. Rudolf, H., \& Watts, J. (2002). Quality of life in substance abuse and dependency. International Review of Psychiatry, 14(3), 190-197.

103. Neale, J., Allen, D., \& Coombes, L. (2005). Qualitative research methods within the addictions. Addiction, 100(11), 1584-1593. 